\title{
Characterization of polyether-poly(methyl methacrylate)-lithium perchlorate blend electrolytes
}

Paula C. Barbosa ${ }^{1}$, Luísa C. Rodrigues ${ }^{1}$, M. Manuela Silva ${ }^{1 *}$, Michael J. Smith $^{1}$, Prudência B. Valente $^{2}$ A. Gonçalves ${ }^{2}$, E. Fortunato ${ }^{2}$

1. Centro de Química, Universidade do Minho, Gualtar, 4710-057 Braga, Portugal

2. Centro de Investigação de Materiais, Universidade Nova de Lisboa, Campus da FCT, 2829-

516 Caparica, Portugal

*nini@quimica.uminho.pt

\begin{abstract}
Solid polymer electrolytes (SPEs) systems based on interpenetrating blends of poly(ethylene oxide-co-propylene oxide) and poly(methyl methacrylate) host matrices, with lithium perchlorate as guest salt, were prepared. These electrolytes were presented as free-standing films, and their thermal and electrochemical properties were characterized by conductivity and electrochemical stability measurements.

The properties of the interpenetrating blends of poly(ethylene oxide-copropylene oxide) and poly(methyl methacrylate) host matrices as the electrolyte component of a solid-state electrochromic device are reported and the results obtained suggest that this electrolyte provides an encouraging performance in this application. The most conducting electrolyte composition of this SPE system is the formulation designated as SPE2-OPC $\left(5.01 \times 10^{-4} \mathrm{~S} \mathrm{~cm}^{-1}\right.$ at about $\left.57^{\circ} \mathrm{C}\right)$. The lowest decomposition temperature was registered with the SPE6-15PC composition $\left(233^{\circ} \mathrm{C}\right)$. The average transmittance in the visible region of the spectrum was above $41 \%$ for all the samples analyzed. After coloration the device assembled with $71 \mathrm{wt} \%$ PC presented an average transmittance of $15.71 \%$ and an optical density at 550nm of 0.61 .
\end{abstract}

Keywords: Polymer Electrolytes, Electrochromic devices, Tungsten Oxide 


\section{INTRODUCTION}

Poly(ethylene oxide) complexed with inorganic salts were first reported as a novel sub-class of solid electrolytes by Fenton, Parker and Wright. ${ }^{[1]}$ Since 1973 these materials have been the object of intense study as solid electrolyte components that may form the basis of future all-solid-state lithium batteries. ${ }^{[2,3]}$ There are however significant problems to overcome. In practical devices, the ionic conduction of the electrolyte component must be raised from values of $10^{-7}-10^{-6} \mathrm{~S} \mathrm{~cm}^{-1}$ typical of firstgeneration SPEs, to values approaching $10^{-3} \mathrm{~S} \mathrm{~cm}^{-1}$ at room temperature. ${ }^{[3]}$ While this value is accessible to "gel" type polymer electrolytes ${ }^{[3]}$, this conductivity performance has not been achieved by "dry" polymer electrolyte systems like PEO. Unlike dry polymer electrolytes, gel polymer electrolyte formulations contain components such as propylene carbonate or ethylene carbonate that are included as additives to enhance ionic conduction. While these liquids in the gel systems certainly increase ion conduction, they also decrease the mechanical stability of the polymer and contribute to the formation of an unstable passivation layer at the lithium/polymer electrolyte interface. $^{[3]}$

Various strategies for improving ionic conduction in polymer electrolytes have been reported, including using polysiloxane and polyphosphazene host matrices with backbone structures and side chains incorporating oxyethylene oligomers. ${ }^{[4-7]} \mathrm{New}$ generation electrolytes have been developed incorporating suitable fillers, novel guest compounds or plasticizing components. ${ }^{[8-15]}$

Electrochromic windows represent one of the most promising applications of SPEs ${ }^{[16-18]}$ where these materials simultaneously function as the ion-conducting layer, sealing surface and adhesive. In this class of electrochemical device the demands placed 
on the conductivity of the electrolyte are not so high because instantaneous color change is not essential in normal device operation.

In this study we report the preparation of solid polymer electrolytes and characterization by measurements of ionic conductivity, differential scanning calorimetry, thermogravimetry and scanning electron microscopy of several different SPEs based on interpenetrating p(EO-PO)/pMMA blends doped with lithium perchlorate and produced by co-deposition from THF. The performance of these SPEs was tested on small-scale solid-state electrochromic windows.

\section{EXPERIMENTAL}

\section{SPE films preparation}

Polymer electrolytes were prepared by combining appropriate amounts of poly(ethylene oxide-co-propylene oxide), p(EO-PO) (supplied by Zeon Corporation Inc.) and poly(methyl methacrylate), pMMA (120,000 $\mathrm{gmol}^{-1}$, Aldrich) with a propylene carbonate (PC) (Aldrich) plasticizer and known quantities of $\mathrm{LiClO}_{4}$ as guest salt. All electrolytes were prepared by solvent casting from THF (Aldrich, anhydrous 99.9\%). Homogeneous solutions of $\mathrm{p}(\mathrm{EO}-\mathrm{PO}), \mathrm{pMMA}, \mathrm{PC}$ and lithium perchlorate were prepared by stirring known masses of electrolyte components in THF for a period of at least 48 hours within a dry argon-filled preparative glovebox. The resulting homogeneous viscous solutions were decanted into rings seated on glass plates and the solvent was removed slowly in an isolated chamber within the preparative glovebox. The atmosphere of this chamber was recirculated through a column of molecular sieves to effect a slow evaporation of the casting solvent and form free-standing films. These electrolyte films were subjected to a final drying procedure in which the temperature was raised from $30^{\circ} \mathrm{C}$ to $60^{\circ} \mathrm{C}$ over a period of 3 days. During this period the tube oven 
was periodically evacuated and purged with dry argon. Solid polymer electrolyte compositions were prepared with the compositions indicated in Table 1.

\section{Transparent conductive oxide (TCO)}

Indium doped zinc oxide films (IZO) were deposited on glass substrates by rf (13.56 MHz) magnetron sputtering using a ceramic oxide target $\operatorname{In}_{2} \mathrm{O}_{3}: \mathrm{ZnO}(92: 8 \mathrm{wt} \%$; $5 \mathrm{~cm}$ diameter, Super Conductor Materials, Suffern, NY, USA) with a purity of $99.99 \%$. Sputtering was carried out at room temperature, with an argon flow of $20 \mathrm{sccm}$ and an oxygen flow of $0.4 \mathrm{sccm}$. During sputtering the deposition pressure (argon and oxygen) was held constant at a value of $0.15 \mathrm{~Pa}$. The distance between the substrate and the target was $10 \mathrm{~cm}$ and the $\mathrm{rf}$ power was maintained at $100 \mathrm{~W}$.

\section{Electrochromic Material}

Tungsten oxide films with thickness of about $300 \mathrm{~nm}$ were deposited on transparent conductive oxide coated glass substrates by rf magnetron sputtering using a $\mathrm{WO}_{3}$ ceramic oxide target from Super Conductor Materials with a purity of $99.99 \%$. Sputtering was carried out at room temperature, under an argon and oxygen atmosphere with a constant deposition pressure of 2.6 Pa. The distance between the substrate and the target was $10 \mathrm{~cm}$ and the rf power was maintained at $200 \mathrm{~W}$.

\section{Electrocromic device struture}

Solid-state electrochromic devices were constructed using a four layer sandwich structure with the following configuration: glass/IZO/ $\mathrm{WO}_{3} /$ polymer electrolyte/IZO/glass. The layers of active material were deposited by rf magnetron sputtering using appropriate targets. Device assembly with electrolytes was carried out by direct application of a small volume of the electrolyte, (10\%) p(EO-PO) / (39\%) 
pMMA / (40\%) PC / (11\%) $\mathrm{LiClO}_{4}$, to the surface of a glass plate onto which a IZO/ $\mathrm{WO}_{3}$ coating had been previously deposited. Typical thicknesses of these layers were $170 \mathrm{~nm}$ for IZO and $400 \mathrm{~nm}$ for $\mathrm{WO}_{3}$. A second glass plate with a IZO coating was placed on top of the electrolyte gel sample and the two plates were pressed together to spread the electrolyte in a thin film between the electrochromic surfaces. In this manner a surface with an area of approximately $2 \mathrm{~cm}^{2}$ was formed. The entire assembly procedure described was carried out under atmospheric conditions.

\section{Measurements}

\subsubsection{DSC and TGA measurements}

Polymer electrolyte sections were removed from cast films and subjected to thermal analysis under a flowing argon atmosphere between 25 and $350{ }^{\circ} \mathrm{C}$ at a heating

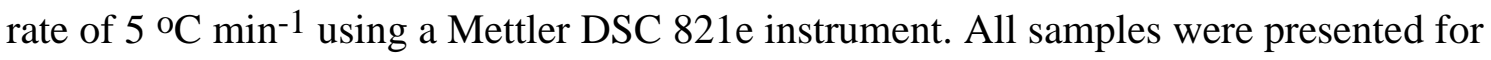
analysis in $40 \mu \mathrm{L}$ aluminium cans with perforated lids to permit the release and removal of the decomposition products. Samples for thermogravimetric studies were prepared in a similar manner, transferred to open platinum crucibles and analyzed using a Rheometric Scientific TG 1000 thermobalance operating under a flowing argon atmosphere. A heating rate of $10{ }^{\circ} \mathrm{C} \mathrm{min}^{-1}$ was used to analyze all the electrolyte samples.

\subsubsection{Impedance spectroscopy}

Total ionic conductivities of electrolyte samples were determined using a constant volume support equipped with gold blocking electrodes and located within a Buchi TO 50 oven. The sample temperature was evaluated by means of a type $\mathrm{K}$ thermocouple placed close to the electrolyte film and impedance measurements were 
carried out at frequencies between $65 \mathrm{kHz}$ and $500 \mathrm{mHz}$ with a Solartron 1250 FRA and $1286 \mathrm{ECI}$, over a temperature range from 20 to $90{ }^{\circ} \mathrm{C}$. Measurements of conductivity were effected during heating cycles. The reproducibility of recorded conductivities was confirmed by comparing the results obtained for a sample subjected to two heatingcooling-heating cycles. This procedure demonstrated the correct operation of the support and the mechanical stability of the samples.

\subsubsection{Optical properties}

The optical transmittance measurements were performed with a Shimadzu UV/VIS 3100PC double beam spectrophotometer in the wavelength range from 380 to $800 \mathrm{~nm}$. The thickness of sample films was measured using a surface profilometer (Dektak 3D from Solan Tech).

\subsubsection{Scanning electron microscopy (SEM)}

X-ray diffraction experiments were carried out using a Bruker-AXS D8 Discover diffractometer in $\theta-2 \theta$ geometry using $\mathrm{Cu} K \alpha 1,2$ lines collimated with a Gobel mirror, a divergent slit of $0.6 \times 10 \mathrm{~mm}^{2}$ and a Ni filter. The data was collected from $10^{\circ}$ to $80^{\circ}$ with a detector slit of $0.2 \times 10 \mathrm{~mm}^{2}$, a step size of $0.04^{\circ}$ and an acquisition time of 0.8 s per step.

\section{RESULTS AND DISCUSSION}

\section{Thermal behaviour of electrolytes}

The DSC thermograms of electrolyte samples represented in Figure 1 confirm that compositions with high p(EO-PO) content (SPE1-0PC, SPE3-9PC, SPE5-15PC, SPE725PC) show broad melting peaks with onsets at about $30^{\circ} \mathrm{C}$. This can be attributed to 
the fusion of the crystalline phase of the $\mathrm{p}(\mathrm{EO}-\mathrm{PO})$ component which is generally complete by about $45^{\circ} \mathrm{C}$. The introduction of substantial quantities of the pMMA and PC components in the network effectively suppressed crystallization of the (EO-PO) components of the electrolytes.

The thermal stability of the electrolyte formulations is influenced by the polymer components, the presence of stabilizing additives and the guest salt concentration. Electrolytes with high pMMA content show a marked tendency to undergo partial decomposition at temperatures close to $200^{\circ} \mathrm{C}$. The lowest decomposition temperature observed is found with the SPE2-0PC composition $\left(186^{\circ} \mathrm{C}\right)$, a value considered acceptable for most foreseeable applications under normal operating conditions. The thermal stability of electrolytes apparently improves with an increase in $\mathrm{p}(\mathrm{EO}-\mathrm{PO})$ and PC content. Samples with substantial quantities of the $\mathrm{p}(\mathrm{EO}-\mathrm{PO})$ component show a major exotehrmic peak at temperatures between about 250 and $325^{\circ} \mathrm{C}$ while electrolyte formulations with less $\mathrm{p}(\mathrm{EO}-\mathrm{PO})$ and more $\mathrm{pMMA}$ tend to decompose at slightly higher temperatures.

The evolution of the glass transition temperatures of the electrolyte samples is illustrated in Figure 2. The addition of the plasticizing component results in a slight decrease of $\mathrm{T}_{\mathrm{g}}$ values. For electrolyte compositions with 15 and $25 \mathrm{wt} \%$ of PC the onset of the $\mathrm{T}_{\mathrm{g}}$ is shifted to lower temperatures. Electrolyte samples, SPE1-0PC and SPE39PC, clearly show two glass transitions, denoted $\mathrm{Tg}_{1}$ and $\mathrm{Tg}_{2}$, indicating the coexistence of two distinct polymer phases.

\section{Ionic conductivity of electrolytes}

Ionic conductivity is an important performance parameter in the development of $\mathrm{p}(\mathrm{EO}-\mathrm{PO}) / \mathrm{pMMA} / \mathrm{LiClO}_{4}$ electrolyte systems for use as multi-functional components in electrochromic devices, such as smart windows. 
The results of conductivity studies of the electrolyte compositions are illustrated in Figure 3 and confirm that the lowest conductivity was registered with compositions rich in $\mathrm{p}(\mathrm{EO}-\mathrm{PO})$ and without plasticizing additive. A significant improvement was observed as a result of the addition of pMMA and/or a plasticizing additive. Encouraging levels of ionic conductivity were found, particularly at temperatures close to ambient, at compositions with higher concentrations of pMMA and plasticizer. The most conducting electrolyte of this SPE system is the SPE2-OPC composition $\left(5.01 \times 10^{-4}\right.$ $\mathrm{S} \mathrm{cm}^{-1}$ at about $57^{\circ} \mathrm{C}$ ), however electrolytes with moderate plasticizer content also show appropriate levels of conductivity and the use of electrolytes with a lower Tg may be expected to improve sealing/adhesive functions and electrode/electrolyte interfacial contact. In optical devices or displays these aspects of electrolyte behavior may become just as relevant as high ionic conductivity.

\section{Scanning electron microscopy (SEM)}

The microphase structure adopted by a blend, and its microscopic appearance, is largely determined by the miscibility of the components. The morphology of the SPE39PC polymer electrolyte was studied by scanning electron microscopy (SEM). Some typical examples of the SEM micrographs are presented in Fig. 4 and 5. The polymer membranes were obtained by evaporating the solvent from the casting solution. In this process, the pore morphology of the polymer membrane is determined by the nature of the solvent, evaporation rate and environmental humidity. The evaporation rate of solvents and the pore size and number can be controlled by adjusting the relative volatility of the casting solvents employed, as reported by Huang and Wunder. ${ }^{[19]}$

Blending $\mathrm{p}(\mathrm{EO}-\mathrm{PO})$ with $\mathrm{pMMA}$ and lithium salt changes the surface morphology from rough to smooth and a reduction of wrinkle is also observed in Fig.4. 
After an appropriate amount of pMMA was incorporated into the $\mathrm{p}(\mathrm{EO}-\mathrm{PO})-\mathrm{LiClO}_{4}$ electrolyte matrix, a further significant improvement in surface morphology is apparent. This may be related to a reduction of crystallinity in the $\mathrm{pEO}$ component as a result of blending with Li salt and pMMA. This interpretation is consistent with DSC results.

Analysis of Figures 4 and 5 suggests that electrolyte sample SPE3-9PC includes spherulites, symmetric arrays of lamellar crystals immersed in the amorphous material. ${ }^{[3]}$ The formation of these spherulites is directly related to the synthetic procedure used to prepare polymer electrolytes (the nature of the solvent, the rate of solvent removal, etc). Figure 5 also shows that this electrolyte composition is of high density and low porosity.

\section{Optical Properties}

Polymer electrolyte films prepared for application in optical devices must meet various pre-requisites. One of these is that the film must exhibit high optical transmission. If this condition is not fulfilled the electrolyte will reduce the color contrast of the device. ${ }^{[20]}$

Figure 6 illustrates the optical transmittance in the wavelength range 400-800 $\mathrm{nm}$ for the prototype electrochromic assembly. Various electrolyte configurations were employed as ionic conducting layers in devices. The objective of this study was to evaluate the influence of the wt $\%$ of PC on the performance of the electrochromic device. Coloring and bleaching voltages of $4 \mathrm{~V}$ and $-4 \mathrm{~V}$ respectively were applied for $20 \mathrm{~s}$ intervals. Table 2 summarizes the average transmittance and the optical density exhibited by devices. The transmittance in the visible region of the spectrum was above $41 \%$ for all the samples analyzed. After coloration the device assembled with $71 \mathrm{wt} \%$ 
PC presented a transmittance of $15.71 \%$ and an optical density at 550nm of 0.61 . Figure 7 illustrates the optical density at $550 \mathrm{~nm}$ for all electrochromic devices.

Figure 8 demonstrates the transparency of the electrolytes produced and shows a prototype solid-state electrochromic device in the coloured state. Prototype electrochromic devices were constructed using a four layer sandwich structure with the following configuration: glass/IZO/WO $/ \mathrm{WO}_{3} /$ polymer electrolyte/IZO/glass. The active layer of the assembled device changed from almost transparent to a blue colour associated with $\mathrm{WO}_{3}$ reduction and simultaneous $\mathrm{Li}^{+}$insertion as a result of the application of a positive voltage. Inversion of the applied voltage resulted in $\mathrm{WO}_{3}$ oxidation and the device returned to its initial state. Cycling tests were performed on all the electrochromic cells, and each cell was cycled (bleached-colored-bleached) 25 times.

\section{CONCLUSIONS}

The preliminary results obtained with combined $\mathrm{p}(\mathrm{EO}-\mathrm{PO})$ with pMMA host matrices and lithium perchlorate are promising. These electrolytes showed good mechanical and electrochemical properties that were improved with the addition of a plasticizer, propylene carbonate. The pMMA and $\mathrm{p}(\mathrm{EO}-\mathrm{PO})$ blend network was found to reduce the tendency of the electrolyte to adsorb moisture and provide good adhesion to a glass substrate. The results obtained with prototype electrochromic devices based on this SPE formulation were encouraging and suggest that polymer electrolytes with these components may, with further development, find application in commercial optical devices. 


\section{ACKNOWLEDGEMENTS}

The authors are pleased to acknowledge the support provided by the University of Minho and the Fundação para a Ciência e a Tecnologia (contracts POCI/QUI/59856/2004, POCTI/SFA/3/686) for laboratory equipment, research staff grants (contracts SFRH/BD/22707/2005 and SFRH/BD/38616/2007) and travel funds (PCB).

\section{REFERENCES}

[1] D.E. Fenton, J.M. Parker, P.V. Wright, Polymer 1973; 14, 589.

[2] P.G. Bruce (Ed.), Solid-state electrochemistry, Cambridge University Press, Cambridge, 1995.

[3] F.M. Gray, Polymer Electrolytes, RSC Materials Monographs, The Royal Society of Chemistry, Cambridge, 1997.

[4] P.M. Blonsky, D.F. Shriver, P.E. Austin and H.R. Allcock, J. Am. Chem. Soc.1984; 106,6854 .

[5] J.R. MacCallum and C.A. Vincent, Editors, Polymer Electrolytes Reviews, London: Elsevier Applied Science. 1987, Ch.1, pp.1-22.

[6] C.J. Nelson, W.D. Coggio, H.R. Allcock, Chem. Mater. 1991; 3, 117.

[7] H.R. Allcock, S.E. Kuharcik, C.S. Reed, M.E. Napierala, Macromolecules 1996; 29, 3384.

[8] S. Vorrey, D. Teeters, Electrochim. Acta 2003; 48, 2137.

[9] M.M. Silva, S.C. Barros, M.J. Smith and J.R. MacCallum, J. Power Sources 2002; 111,52 .

[10] Armand, M., Gorecki, W., Andreani, R. in Second International Meeting on Polymer Electrolytes (ed. Scrosati, B.),Elsevier, London, 1989, 91-96.

[11] D. Benrabah, D. Baril, J.Y. Sanchez and M. Armand, J. Chem. Soc., Faraday Trans 1993; 89, 355.

[12] K. Xu, S.S. Zhang, T.R. Jow, W. Xu and C.A. Angell, Electrochem. Solid State Lett. 2002; 5, A26. 
[13] M. Schmidt, U. Heider, A. Kuehner, R. Oesten, M. Jungnitz, N. Ignatev and P. Sartori, J. Power Sources 2001; 97-98, 557.

[14] J.S. Gnanaraj, M.D. Levi, Y. Gofer and D. Aurbach, J. Electrochem. Soc. 2003; $150,445$.

[15] F. Kita, H. Sakata, S. Sinomoto, A. Kawakami, H. Kamizori, T. Sonoda, H. Nagashima, J. Nie, N.V. Pavlenko and Y. L. Yagupolskii, Journal of Power Sources 2000; 90, 27.

[16] M.-A. de Paoli, A. Berlin, A. Geri, G. C. Miceli, W.A. Gazotti, Adv. Mater. 1998; $10,1522$.

[17] M.-A. de Paoli, A.F. Nogueira, D.A. Machado, Claudia Longo, Electrochimica Acta 2001; 46, 4243.

[18] C.O. Avellaneda, D.F. Vieira, A.Al-Kahlout, S. Heusing, E.R. Leite, A. Pawlicka, M.A. Aegerter, Solar Energy Materials and Solar Cells 2008; 92, 228.

[19] H. Huang and S. L. Wunder, Journal Power Sources 2001; 97-98, 649.

[20] M-H. Cui, Jun-Shi Guo, H-Q. Xie, Z-H. Wu, S-C. Qiu, Journal of Applied Polymer Science 1997; 65, 1739.

Table 1 - Electrolyte compositions based on p(EO-PO), pMMA, PC and $\mathrm{LiClO}_{4}$.

\begin{tabular}{ccccc}
\hline$(\mathbf{w t} \%) \mathbf{p}(\mathbf{E O}-\mathrm{PO})$ & $(\mathbf{w t} \%) \mathbf{p M M A}$ & $(\mathbf{w t} \%) \mathbf{P C}$ & $(\mathbf{w t} \%) \mathbf{L i C l O}_{\mathbf{4}}$ & Sample \\
\hline 80 & 9 & 0 & 11 & SPE1-0PC \\
9 & 80 & 0 & 11 & SPE2-0PC \\
62 & 18 & 9 & 11 & SPE3-9PC \\
18 & 62 & 9 & 11 & SPE4-9PC \\
59 & 15 & 15 & 11 & SPE5-15PC \\
15 & 59 & 15 & 11 & SPE6-15PC \\
54 & 10 & 25 & 11 & SPE7-25PC \\
10 & 54 & 25 & 11 & SPE8-25PC \\
\hline
\end{tabular}


Table 2 - Average transmittance and optical density exhibited by electrochromic devices.

\begin{tabular}{cccc}
\hline$(\mathbf{w t} \%) \mathbf{P C}$ & $\begin{array}{c}\text { Transmittance in } \\
\text { bleached state (\%) }\end{array}$ & $\begin{array}{c}\text { Transmittance in } \\
\text { colored state }(\mathbf{\%})\end{array}$ & $\begin{array}{c}\text { Optical density } \\
\mathbf{( 5 5 0} \mathbf{~ n m})\end{array}$ \\
\hline $\mathbf{0}$ & 54.19 & 16.57 & 0.49 \\
$\mathbf{9}$ & 52.59 & 24.21 & 0.34 \\
$\mathbf{1 5}$ & 47.09 & 17.88 & 0.35 \\
$\mathbf{2 0}$ & 41.49 & 16.96 & 0.36 \\
$\mathbf{4 0}$ & 61.59 & 19.58 & 0.46 \\
$\mathbf{7 1}$ & 73.44 & 15.71 & 0.61 \\
\hline
\end{tabular}




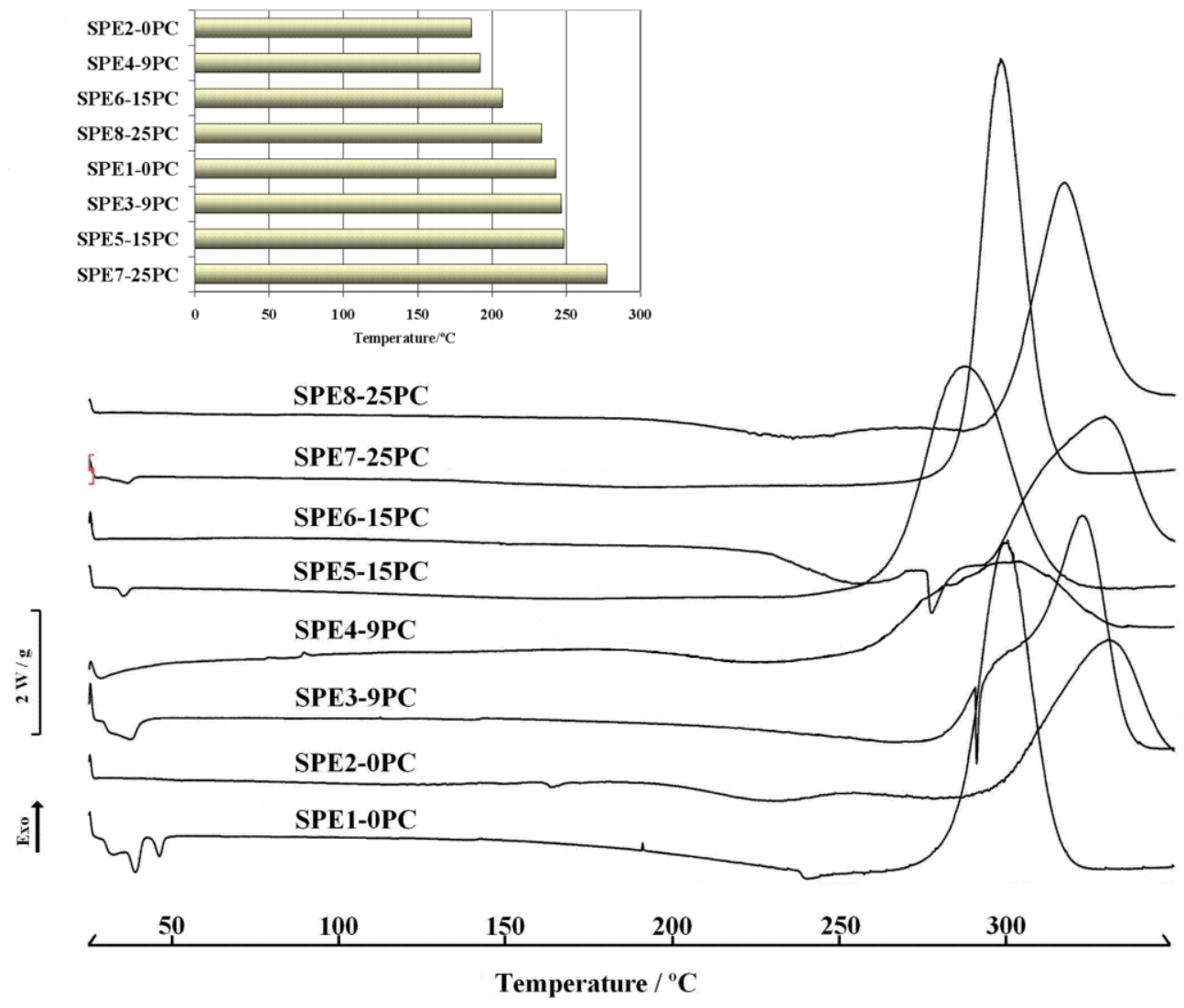

Figure 1. DSC thermograms of $\mathrm{p}(\mathrm{EO}-\mathrm{PO}) / \mathrm{pMMA} / \mathrm{LiClO}_{4}$ electrolytes. 


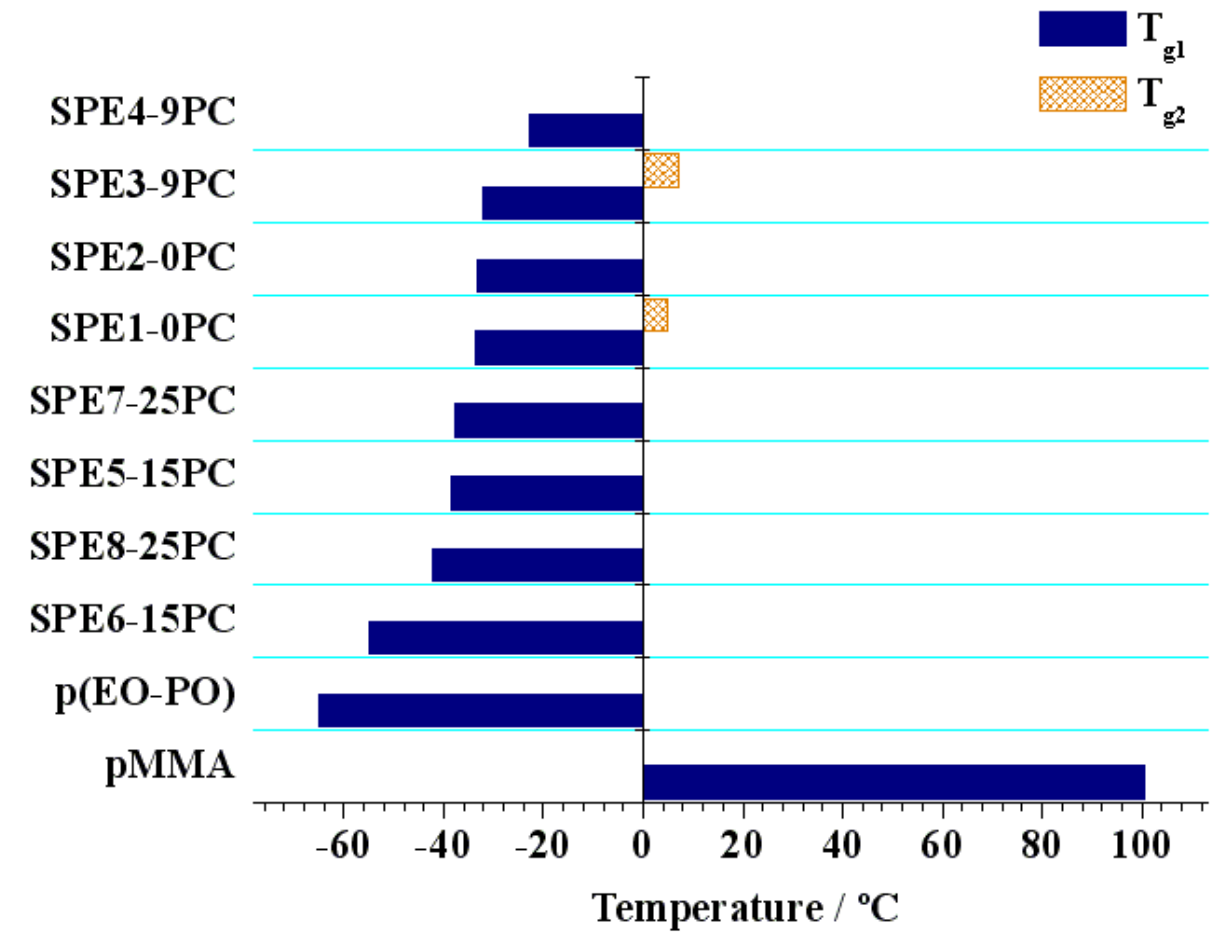

Figure 2. $\mathrm{Tg}$ of $\mathrm{p}(\mathrm{EO}-\mathrm{PO}) / \mathrm{pMMA} / \mathrm{LiClO}_{4}$ electrolytes. 


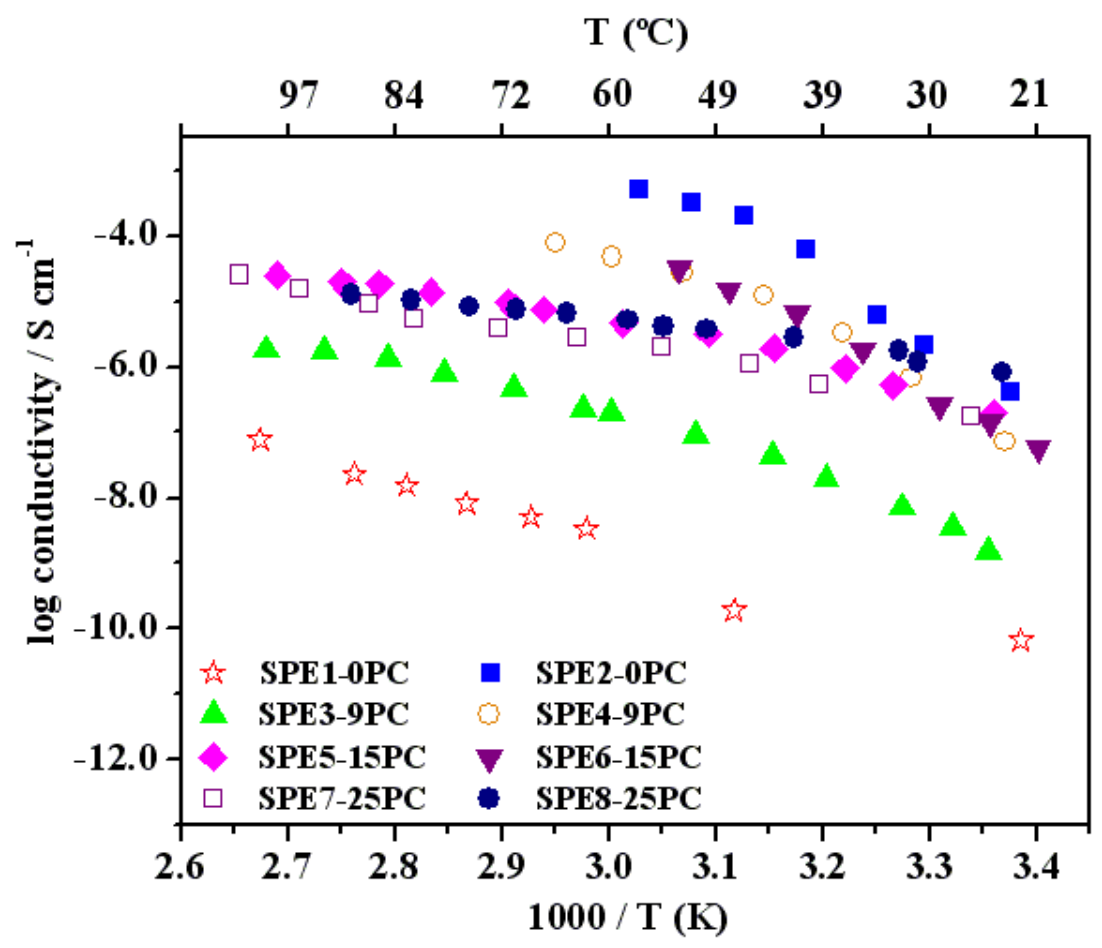

Figure 3. Variation of conductivity of $\mathrm{p}(\mathrm{EO}-\mathrm{PO}) / \mathrm{pMMA} / \mathrm{LiClO}_{4}$ electrolytes with temperature. 


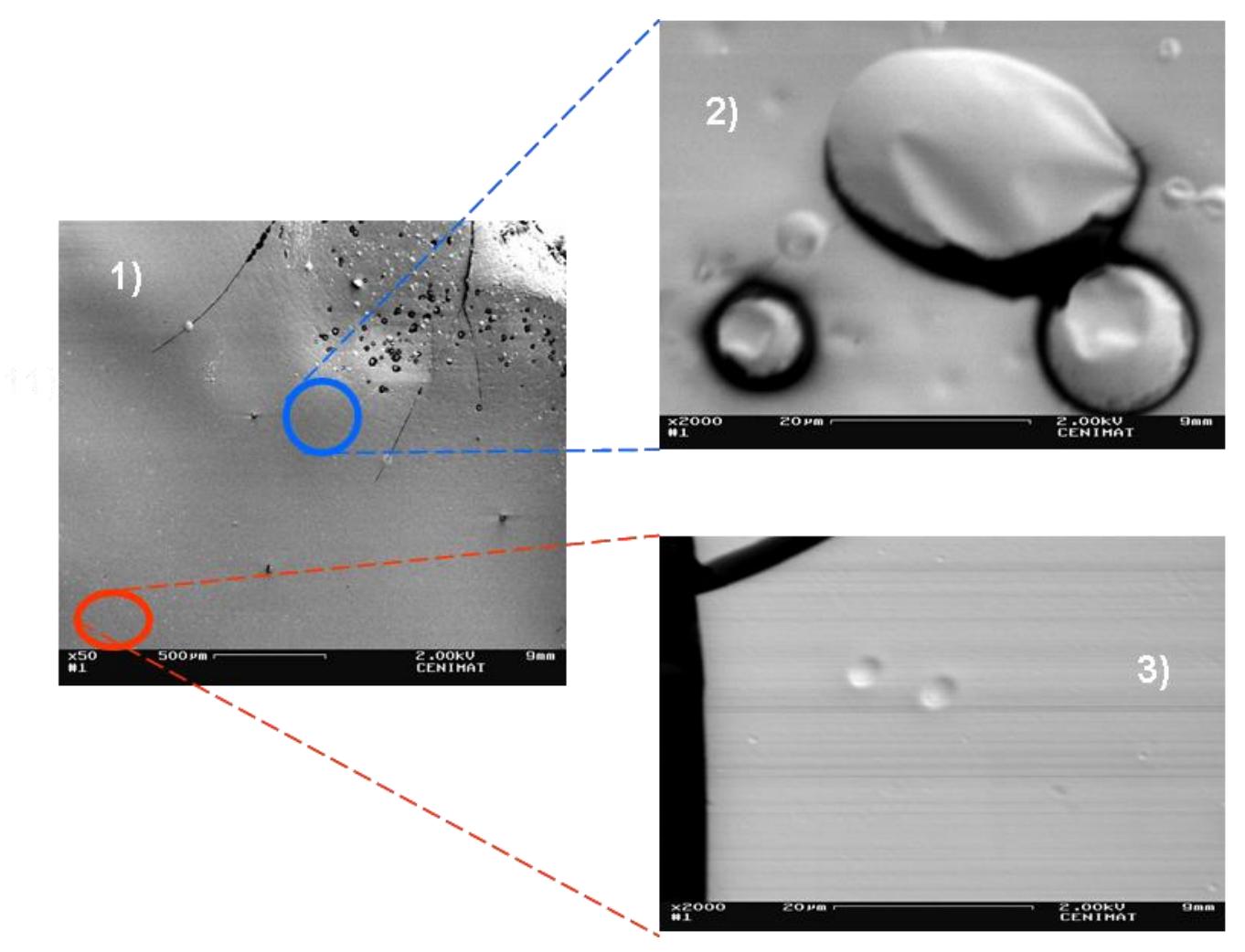

Figure 4. Selected SEM photographs of morphology of upper surface of SPE3-9PC (x50) (1) and two magnifications (x2000) of the areas identified as (2) and (3). 

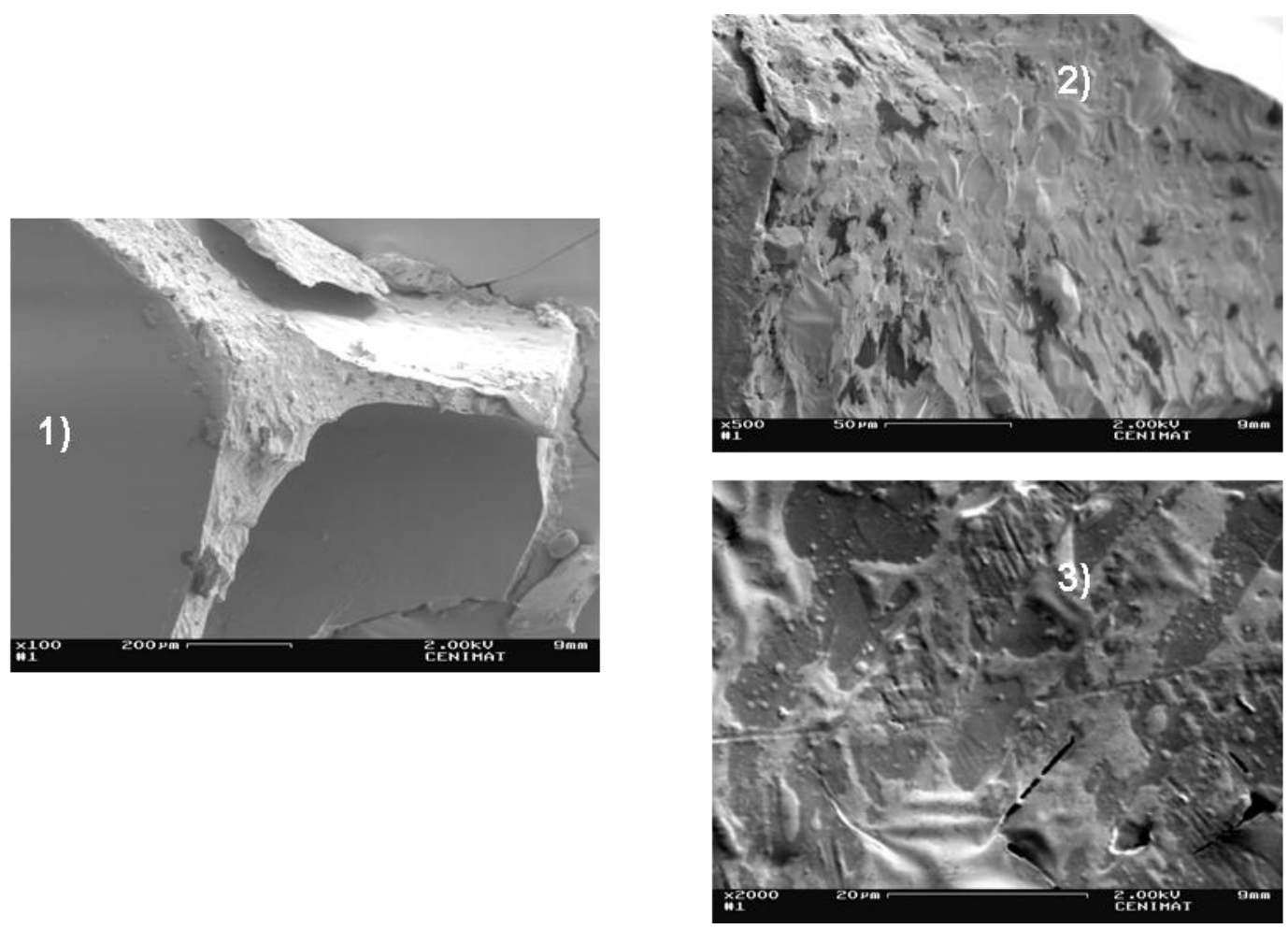

Figure 5. Scanning electron microscope (SEM) images of SPE3-9PC, cross-sectional view, (x100) (1) and two images at different locations of the observed area (x500) (2) and (x2000) (3). 

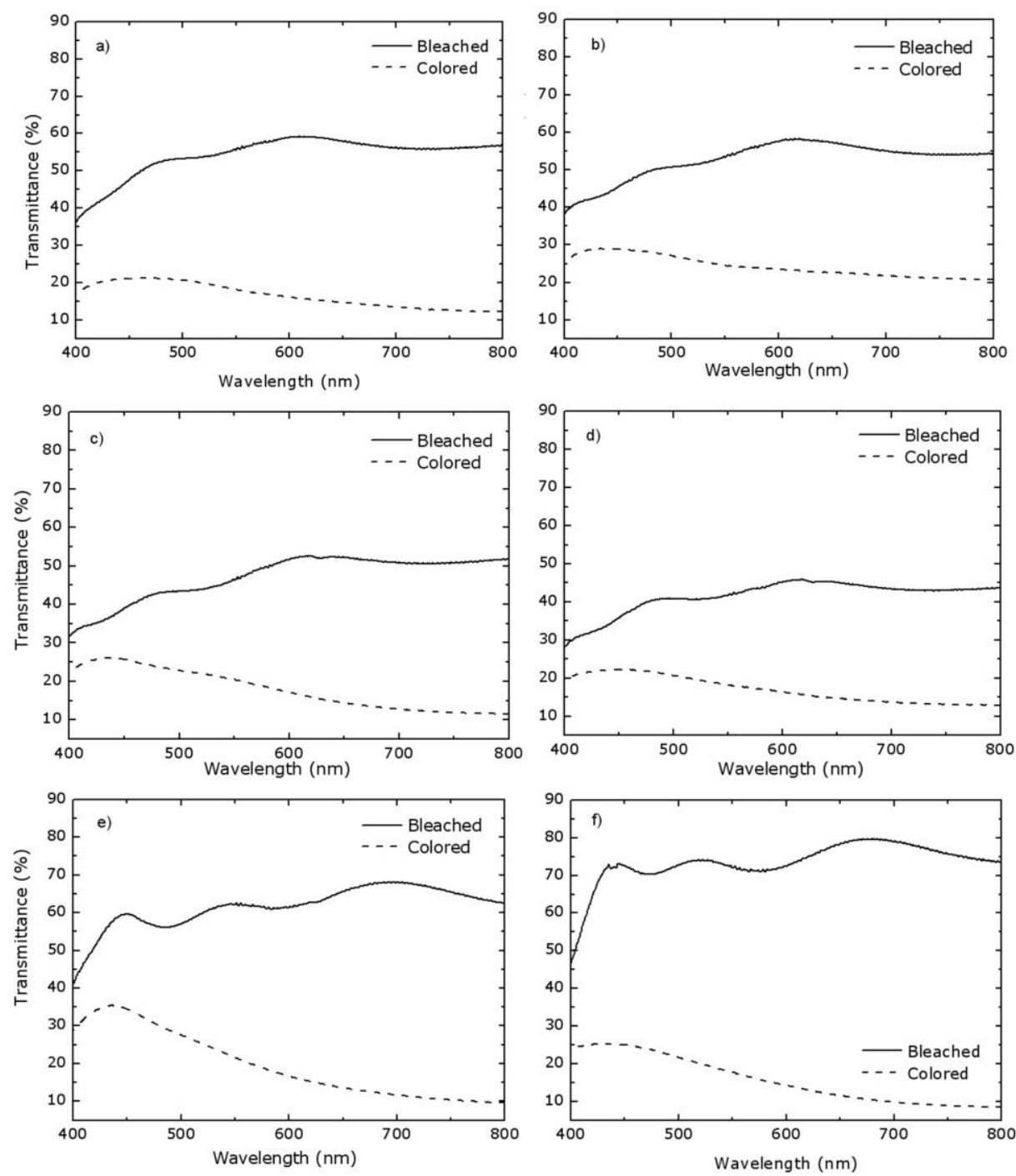

Figure 6. Optical transmittance as a function of wavelength for the electrochromic device assembly in bleached and colored states using (a) $0 \mathrm{wt} \%$ PC; (b) 9 wt \% PC; (c) 15 wt $\%$ PC; (d) 20 wt \% PC; (e) 40 wt \% PC; (f) 71 wt \% PC. 


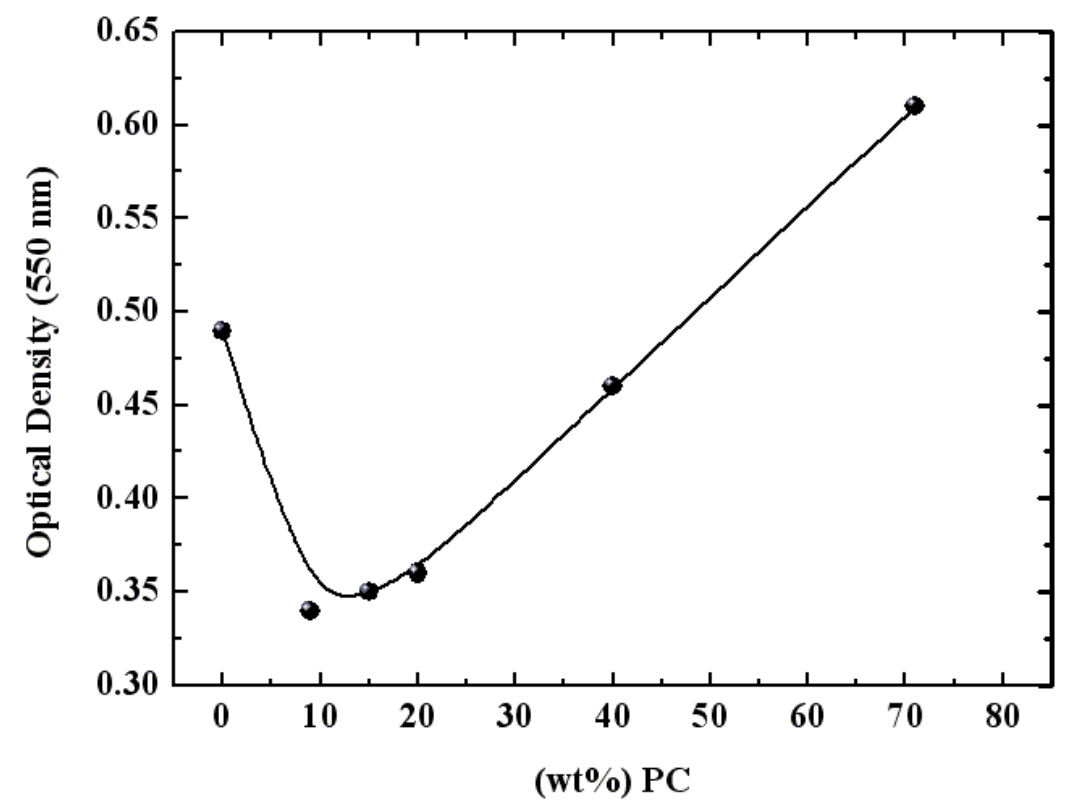

Figure 7. Optical density versus wt\% PC. 


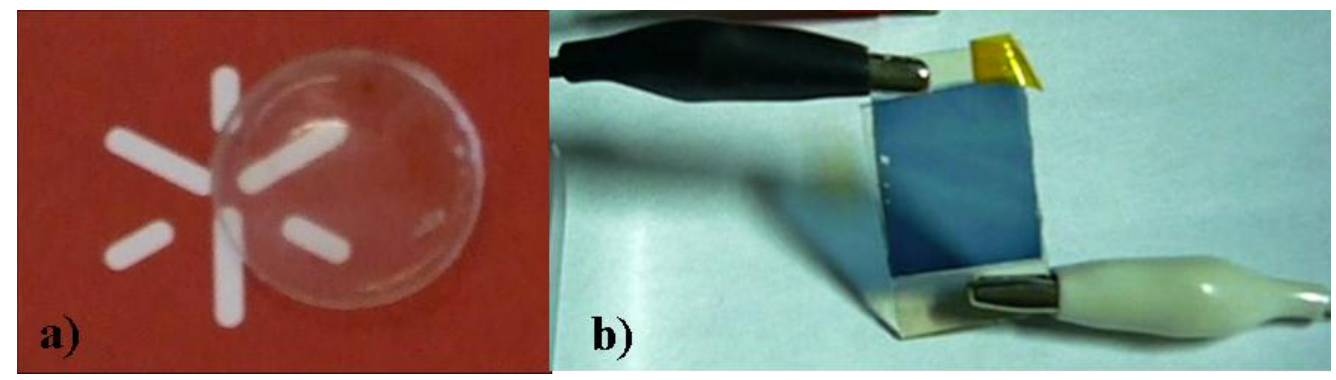

Figure 8. a) p(EO-PO)/pMMA/PC/LiClO 4 electrolyte; b)Prototype electrochromic device based on (10\%) p(EO-PO) / (39\%) pMMA / (40\%) PC / (11\%) $\mathrm{LiClO}_{4}$ electrolyte, in the colored state. 